\title{
Temporary right ventricular mechanical circulatory support for the management of right ventricular failure in critically ill patients
}

\author{
Nadia Aissaoui, MD, ${ }^{\mathrm{a}, \mathrm{b}}$ Michiel Morshuis, MD, ${ }^{\mathrm{a}}$ Michael Schoenbrodt, MD, ${ }^{\mathrm{a}}$ \\ Kavous Hakim Meibodi, MD, ${ }^{a}$ Lukasz Kizner, MD, ${ }^{a}$ Jochen Börgermann, MD, $\mathrm{PhD},{ }^{a}$ and \\ Jan Gummert, MD, $\mathrm{PhD}^{\mathrm{a}}$
}

\begin{abstract}
Background: Management of right ventricular (RV) failure after left ventricular assist device (LVAD) implantation is not evidence based. Temporary circulatory assistance has recently been reported to be of value for managing postoperative RV failure after LVAD implantation, but only in small series of patients or isolated case reports. We report here our experience with the use of temporary right ventricular assist devices (RVADs) in LVAD recipients.
\end{abstract}

Methods: Forty-five of the 488 (9\%) patients undergoing LVAD implantation between 2001 and 2011 at the Clinic for Thoracic and Cardiovascular Surgery in Bad Oeynhausen had RV failure requiring temporary RVAD. We analyzed preoperative data, complications, mortality at 6 months, and risk factors of death.

\begin{abstract}
Results: The LVAD patients receiving temporary RVAD were younger than the 443 recipients of LVAD alone. They were more likely to have mechanical ventilation and haemofiltration and their Michigan right ventricular risk score was higher. The LVAD patients with temporary RVAD had a higher mortality at 6 months: $53 \%$, versus $25 \%$ for patients receiving LVAD only $(P<.001)$. The univariate risk factors for death were high blood urea nitrogen and C-reactive protein concentrations, preoperative mechanical ventilation, preoperative hemofiltration, destination therapy, the use of temporary RVAD, and the development of RV failure. Multivariate analyses did not identify predictors of death.
\end{abstract}

Conclusions: The development of RV failure in LVAD recipients is a serious problem associated with high mortality. Temporary RV mechanical support is an acceptable way to manage postoperative RV failure in these severely ill LVAD recipients. (J Thorac Cardiovasc Surg 2013;146:186-91)

The ventricular assist device (VAD) has become a lifesaving therapeutic option for patients with end-stage heart failure. ${ }^{1}$ The occurrence of right ventricular (RV) failure after implantation of a left ventricular assist device (LVAD) is associated with significant perioperative mortality and morbidity. ${ }^{2,3}$ Many factors contribute to RV failure after LVAD implantation, complicating the prediction and management of postoperative RV dysfunction.

Management of RV failure after LVAD implantation is not evidence-based. Biventricular mechanical support (BiVAD) is effective but associated with lower survival and a worse quality of life than left ventricular support only. The course of BiVAD is complicated by high rates of major adverse events, such as thromboembolism, device infections, and mechanical complications. ${ }^{4,5}$

From the Heart \& Diabetes Center, ${ }^{\text {a }}$ North Rhine-Westphalia, Bad Oeynhausen, Germany; and the European Georges Pompidou Hospital, ${ }^{\mathrm{b}}$ Paris, France.

Disclosures: Authors have nothing to disclose with regard to commercial support.

Received for publication July 16, 2012; revisions received Dec 20, 2012; accepted for publication Jan 28, 2013; available ahead of print Feb 25, 2013.

Address for reprints: Nadia Aissaoui, MD, European Georges Pompidou Hospital,

25 rue Leblanc, 75015 Paris, France (E-mail: nadia.aissaoui@egp.aphp.fr).

$0022-5223 / \$ 36.00$

Copyright (c) 2013 by The American Association for Thoracic Surgery

http://dx.doi.org/10.1016/j.jtcvs.2013.01.044
RV failure after LVAD implantation can also be managed by treating the patient with pulmonary vasodilators and inotropes, but such drug-based treatment may prove insufficient. $^{6}$

The implantation of a temporary RV assist device (RVAD) has recently been shown to be of value for managing postoperative RV failure after LVAD implantation. However, reports to date have been limited to small series of patients or isolated case reports. ${ }^{7-12}$

We describe here our experience at Bad Oeynhausen with the management, by temporary RV mechanical circulatory support of patients with an LVAD in whom RV failure develops after surgery.

\section{METHODS \\ Data Collection}

Study coordinators, bioengineers, and physicians systematically and prospectively entered all demographic and clinical data, including all laboratory test results, adverse events, device-related complications and malfunctions, and long-term outcomes, into a database at the time of VAD implantation or registration on the waiting list for transplantation. This study was carried out in accordance with the Helsinki Declaration; its database was designed for clinical purposes and for research protocols approved by the appropriate institutional review board. It was not necessary to seek informed consent from patients inasmuch as this observational study did not modify diagnostic testing or therapeutic interventions. 


\section{Abbreviations and Acronyms \\ BiVAD = biventricular mechanical support \\ LVAD $=$ left ventricular assist device \\ $\mathrm{RV} \quad=$ right ventricular \\ RVAD = right ventricular assist device \\ $\mathrm{VAD}=$ ventricular assist device}

\section{Study Participants}

The data were collected prospectively for all patients undergoing VAD implantation between 2001 and April 2011 at the Clinic for Thoracic and Cardiovascular Surgery of Bad Oeynhausen (Germany) and were analyzed retrospectively. During the study period, 488 patients underwent LVAD implantation. RV failure developed in 77 of these patients, and the 45 patients requiring temporary RVAD were included in our study. All cases of planned BiVAD were excluded. The BiVAD group comprised 69 patients for whom the decision to implant VAD bilaterally was taken before surgery and 15 LVAD recipients who could not be weaned from cardiopulmonary bypass.

\section{Definition and Management of RV Failure}

$\mathrm{RV}$ failure was defined as RV dysfunction requiring an RVAD or 14 days or more of nitrous oxide or inotropic support after LVAD implantation. The decision to implant an RVAD was made by a heart surgeon in consultation with a cardiologist specializing in heart failure. This decision was based on multiple factors, including overall clinical status, patient size, transplant eligibility, device availability, expected duration of support, and patient preference.

In all cases, postoperative RV failure in LVAD recipients was initially managed with drugs: a vasodilator, such as nitroprusside, nitrous oxide, or iloprost, and an inotrope, such as milrinone, dobutamine, or epinephrine. If RV function continued to deteriorate and was accompanied by high central venous pressure, leading to insufficient loading of the left ventricle, low output, and a decrease in organ perfusion, a temporary RVAD was implanted at the same time or a few days after LVAD implantation in patients who were expected to be weaned from the RVAD.

\section{Temporary RVAD Implantation}

At our center in Bad Oeynhausen, we perform end-to-side anastomosis with an 8-mm Hemashield graft (St Jude Medical, Inc, St Paul, Minn) and the pulmonary artery. The graft is tunneled through the skin. The outflow cannula is inserted over the graft. The inflow cannula is inserted into the femoral vein, and the Seldinger technique is used to position the cannula in the right atrium. This method has the advantage that it can be performed under local anesthesia in the intensive care unit. It is not necessary to open the chest.

The temporary RVAD was implanted in the perioperative period if weaning from bypass proved impossible (early RVAD) or after this period (late RVAD). We divided the group of patients with temporary RVAD into 2 subgroups on the basis of the timing of device insertion: (1) early temporary $\operatorname{RVAD}(n=20)$ and late temporary $\operatorname{RVAD}(n=25)$. In the late temporary RVAD subgroup, 17 LVAD recipients underwent temporary RVAD insertion during the first week after LVAD implantation, and 8 patients underwent this procedure more than 1 week after LVAD insertion.

\section{Temporary RVAD Management}

The temporary RVAD was removed when the patients had no need for an escalation of inotropic support, low central venous pressure, and an improvement of RV systolic function on echocardiography. Echocardiography was used to assess the feasibility of RVAD removal. RVAD removal was considered when LVAD flow did not decrease when we reduced RVAD flow and echocardiographic evaluation showed no RV dilatation.

Patients showing no recovery of RV function after 7 to 14 days were switched to permanent RVAD or were placed on the list for high emergency heart transplantation if suitable for this procedure.

\section{Devices}

For LVAD recipients with temporary RVAD, we used 9 HeartMate XVE and 9 HeartMate II devices (Thoratec Corporation, Pleasanton, Calif), 13 HeartWare ventricular assist systems, 5 VentrAssist (Ventracor, Ltd, Chatswood, Australia), 5 DuraHeart (Terumo Heart, Inc, Ann Arbor, Mich), and 4 Novacor (Novacor Division of Baxter Healthcare Corp, Oakland, Calif) devices.

For the other 443 LVAD recipients, we used 50 HeartMate XVE and 111 HeartMate II devices (Thoratec), 75 HeartWare ventricular assist systems (HeartWare, Inc, Framingham, Mass), 47 VentrAssist devices (Ventracor), 74 DuraHeart devices (Terumo Heart), 53 Novacor devices (Novacor Division of Baxter Healthcare Corp), 18 CorAide devices (The Cleveland Clinic Foundation, Cleveland, Ohio), 9 LionHeart left ventricular assist systems (Arrow International, Reading, Pa), 4 Incor devices (Berlin Heart AG, Berlin, Germany), and 2 DeBakey VADs (MicroMed Cardiovascular, Inc, Houston, Tex).

For short-term RVAD, we initially used 19 Thoratec PVAD devices. Subsequently, from 2005, we used 26 CentriMag RVADs (Levitronix LCC, Waltham, Mass) with an extracorporeal magnetically levitated radial pump.

\section{Patient Characteristics and VAD Implantation}

Preoperative data, including demographic and clinical characteristics, echocardiographic and hemodynamic measurements, laboratory test results and numbers of inotropes, the day of LVAD implantation and need for mechanical ventilation, hemofiltration, inotropic drugs, and intraarterial balloon pump support were analyzed. The Michigan RV risk score was calculated for each patient. ${ }^{4}$ This score assigns points for 4 variables, with vasopressor use adding 4 points, creatinine concentration of more than $2.3 \mathrm{mg} / \mathrm{dL}$ adding 3 points, bilirubin concentration of more than $2 \mathrm{mg} / \mathrm{dL}$ adding 2.5 points, and aspartate aminotransferase levels of more than $80 \mathrm{IU} / \mathrm{dL}$ adding 2 points. Higher scores $(\geq 5.5)$ are associated with a greater risk of RV failure.

\section{Outcome Data}

Complications included acute renal failure, sepsis, adverse cerebral events, reoperation for bleeding, pump malfunction, and arrhythmia Cerebral complications included cerebral hemorrhage, transient ischemia, and cerebral vascular accident. The dates of device implantation, weaning from temporary RVAD, and transplantation were recorded. Vital status was recorded at 6 months and risk factors for death were identified.

\section{Statistical Analysis}

The data are expressed as means \pm standard deviation and numbers and percentages for categorical variables. The Student $t$ test, Mann-Whitney tests, $\chi^{2}$ tests, and Fisher's exact tests were used for comparisons, as appropriate. We compared findings for LVAD recipients with and without temporary RVAD and according to the time of RVAD implantation. Survival for the temporary RVAD groups was reported graphically using the KaplanMeier method. A univariate analysis was performed to identify factors associated with mortality at 6 months. Multivariate analyses of predictors of death were performed using stepwise multiple logistic regression analysis. Variables included in the multivariate analyses were selected on their significance $(P<.05)$ in univariate analyses.

The data were analyzed with the commercially available Statview statistical package, version 5.0 (SAS Institute, Inc, San Francisco, Calif) and XLSTAT (Addinsoft, Andernach, Germany). 
TABLE 1. Baseline characteristics of the population

\begin{tabular}{|c|c|c|c|}
\hline & $\begin{array}{l}\text { LVAD patients } \\
\text { with temporary } \\
\text { RVAD }(\mathrm{N}=45)\end{array}$ & $\begin{array}{c}\text { LVAD } \\
\text { recipients } \\
(\mathrm{N}=\mathbf{4 4 3}) \\
\end{array}$ & $\begin{array}{c}P \\
\text { value } \\
\end{array}$ \\
\hline Age, y & $53 \pm 14$ & $56 \pm 13$ & .03 \\
\hline Men, n (\%) & $37(82)$ & $289(65)$ & .02 \\
\hline \multicolumn{4}{|l|}{ Primary diagnosis $n(\%)$} \\
\hline Ischemic cardiomyopathy & $24(53)$ & $233(53)$ & NS \\
\hline Dilated cardiomyopathy & $19(42)$ & $170(38)$ & NS \\
\hline Other & $2(5)$ & $40(9)$ & NS \\
\hline \multicolumn{4}{|l|}{ Intention to treat, $\mathrm{n}(\%)$} \\
\hline Bridge to transplantation & $35(78)$ & $309(70)$ & NS \\
\hline Destination therapy & $10(22)$ & $115(26)$ & NS \\
\hline History of heart surgery, n (\%) & $18(40)$ & $138(31)$ & NS \\
\hline LV ejection fraction, $\%$ & $21 \pm 6$ & $22 \pm 8$ & NS \\
\hline Cardiac index, $\mathrm{L} \cdot \min ^{-1} \cdot \mathrm{m}^{-2}$ & $2.0 \pm 0.5$ & $2.2 \pm 0.6$ & NS \\
\hline CVP, mm Hg & $12 \pm 5$ & $11 \pm 6$ & NS \\
\hline Mean PAP, $\mathrm{mm} \mathrm{Hg}$ & $33 \pm 14$ & $31 \pm 10$ & NS \\
\hline PVR, dynes $\cdot \mathrm{s} \cdot \mathrm{cm}^{-5}$ & $323 \pm 174$ & $249 \pm 159$ & NS \\
\hline SVR, dynes $\cdot \mathrm{s} \cdot \mathrm{cm}^{-5}$ & $1194 \pm 394$ & $1136 \pm 480$ & NS \\
\hline PCPW, mm Hg & $23 \pm 9$ & $20 \pm 8$ & NS \\
\hline Bilirubin, mg/dL & $2.2 \pm 0.7$ & $1.6 \pm 0.7$ & $<.01$ \\
\hline Aspartate aminotransferase, IU/L & $159 \pm 53$ & $76 \pm 23$ & $<.01$ \\
\hline BUN, mg/dL & $80 \pm 28$ & $78 \pm 47$ & NS \\
\hline Creatinine, $\mathrm{mg} / \mathrm{L}$ & $1.7 \pm 0.9$ & $1.6 \pm 0.9$ & NS \\
\hline $\mathrm{CRP}, \mathrm{mg} / \mathrm{L}$ & $7.9 \pm 11.6$ & $5.36 \pm 6.28$ & NS \\
\hline No. of inotropes & $2.4 \pm 1.2$ & $2.2 \pm 0.9$ & NS \\
\hline IABP, n (\%) & $27(63)$ & $180(41)$ & .02 \\
\hline Mechanical ventilation, n (\%) & $15(34)$ & $80(18)$ & .01 \\
\hline Hemofiltration, $\mathrm{n}(\%)$ & $16(38)$ & $79(18)$ & $<.001$ \\
\hline Michigan RV risk score & $2.9 \pm 2.6$ & $1.7 \pm 2.5$ & $<.001$ \\
\hline \multicolumn{4}{|c|}{$\begin{array}{l}\text { Data are expressed as means } \pm \text { standard deviation. } L V A D \text {, Left ventricular assist } \\
\text { device; } R V A D \text {, right ventricular assist device; } L V \text {, left ventricular; } C V P \text {, central venous } \\
\text { pressure; } P A P \text {, pulmonary artery pressure; } P V R \text {, pulmonary vascular resistance; } \\
S V R \text {, systemic vascular resistance; } P C W P \text {, pulmonary capillary wedge pressure; } \\
B U N \text {, blood urea nitrogen; } C R P \text {, C-reactive protein; } I A B P \text {, intra-aortic balloon } \\
\text { pump; } R V \text {, right ventricular; } N S \text {, not significant. }\end{array}$} \\
\hline
\end{tabular}

\section{RESULTS}

Baseline Characteristics of the LVAD Patients, as a Function of the Presence or Absence of Temporary RVAD

The baseline characteristics of the patients are shown in Table 1. The LVAD patients with temporary RVAD were younger than those without temporary RVAD. They were also more likely to have a preoperative intra-aortic balloon pump, mechanical ventilation, and hemofiltration, and their Michigan RV risk scores were higher.

\section{Outcome of the Patients as a Function of the Presence or Absence of Temporary RVAD}

The postoperative adverse events observed are reported in Table 2. The LVAD recipients with temporary RVAD were more likely to have postoperative bleeding requiring reoperation and acute renal failure. Mortality at 6 months was higher for LVAD patients with temporary RVAD than for those without RVAD: $53 \%$ in the LVAD patients with
TABLE 2. Adverse events

\begin{tabular}{lcc}
\hline & $\begin{array}{c}\text { LVAD patients with } \\
\text { temporary RVAD, }\end{array}$ & LVAD patients, \\
Adverse events, n (\%) & $\mathbf{N}=\mathbf{4 5}$ & $\mathbf{N}=\mathbf{4 4 3}$ \\
\hline Reoperation for bleeding & $27(60)$ & $90(20)^{*}$ \\
Acute renal failure & $33(73)$ & $166(28)^{*}$ \\
Stroke & $10(22)$ & $126(28)$ \\
Cerebral hemorrhage & $7(16)$ & $40(9)$ \\
Transient ischemia & $1(2)$ & $39(9)$ \\
Cerebral vascular accident & $2(4)$ & $47(11)$ \\
Sepsis & $16(36)$ & $160(36)$ \\
Arrythmia & $13(30)$ & $98(22)$ \\
Device malfunction & $2(4)$ & $91(20)^{*}$ \\
\hline$L V A D$, Left ventricular assist device; $R V A D$, right ventricular assist device. $* P<.05$
\end{tabular}

temporary RVAD versus $25 \%$ in patients with LVAD only $(P<.001)$.

\section{Risk Factors for Death}

The univariate risk factors for death were high blood urea nitrogen and C-reactive protein concentrations, preoperative mechanical ventilation, preoperative hemofiltration, destination therapy, the use of temporary RVAD, and the development of RV failure (Table 3). Multivariate analyses did not identify predictors of death.

\section{Baseline Characteristics as a Function of the Timing of RVAD Implantation}

Baseline characteristics were similar in LVAD patients with early temporary RVAD $(n=20)$ and LVAD patients with late temporary RVAD $(n=25)$ (Table 4$)$.

\section{Outcome of the Patients as a Function of the Timing of RVAD Implantation}

The median duration of temporary RVAD support was similar in the 2 groups: 21 days (range, 7-90 days) in the early temporary RVAD group versus 33 days (range, 12147 days) in the late temporary RVAD group $(P=.054)$. The incidence of complications was also similar in the 2 groups (Table 4). The 6-month Kaplan-Meier actuarial survival was $50 \%$ in the early temporary RVAD group

TABLE 3. Risk factors for death

\begin{tabular}{lccr}
\hline \multicolumn{1}{c}{ Factors } & OR for death & $\mathbf{9 5} \%$ CI & P value \\
\hline Destination therapy & 7.39 & $4.09-13.4$ & $<.0001$ \\
Temporary RVAD & 3.43 & $1.77-6.67$ & .0001 \\
Postoperative RV failure & 2.85 & $1.68-4.87$ & $<.0001$ \\
$\mathrm{CRP}>2.3 \mathrm{mg} / \mathrm{l}$ & 2.41 & $1.59-3.65$ & $<.0001$ \\
BUN $>62 \mathrm{mg} / \mathrm{dl}$ & 2.28 & $1.51-3.45$ & $<.0001$ \\
Preoperative hemofiltration & 1.82 & $1.09-3.03$ & .02 \\
Preoperative MV & 1.70 & $1.00-2.90$ & .003 \\
\hline
\end{tabular}

$O R$, Odds ratio; $C I$, confidence interval; $R V A D$, right ventricular assist device; $R V$, right ventricular; $C R P$, C-reactive protein; $B U N$, blood urea nitrogen; $M V$, mechanical ventilation. 
TABLE 4. Baseline characteristics as a function of the timing of RVAD implantation

\begin{tabular}{|c|c|c|c|}
\hline Temporary RVAD & $\begin{array}{l}\text { Early RVAD } \\
\text { implantation } \\
\quad(\mathbf{n}=\mathbf{2 0})\end{array}$ & $\begin{array}{c}\text { Late RVAD } \\
\text { implantation } \\
(n=25)\end{array}$ & $\begin{array}{c}P \\
\text { value } \\
\end{array}$ \\
\hline Age, y & $53.5 \pm 16.3$ & $51.9 \pm 10.8$ & NS \\
\hline Men, n (\%) & $13(81)$ & $10(90)$ & NS \\
\hline \multicolumn{4}{|l|}{ Primary diagnosis, $\mathrm{n}(\%)$} \\
\hline Ischemic cardiomyopathy & $6(38)$ & $7(64)$ & NS \\
\hline Dilated cardiomyopathy & $8(50)$ & $4(36)$ & NS \\
\hline Other & $2(12)$ & 0 & NS \\
\hline \multicolumn{4}{|l|}{ Intention to treat $\mathrm{n}(\%)$} \\
\hline Bridge to transplantation & $14(88)$ & $8(73)$ & NS \\
\hline Destination therapy & $2(12)$ & $3(27)$ & NS \\
\hline History of heart surgery, n (\%) & $8(50)$ & $2(18)$ & .04 \\
\hline LV ejection fraction, $\%$ & $19 \pm 9$ & $18 \pm 4$ & NS \\
\hline Cardiac index, $\mathrm{L} \cdot \min ^{-1} \cdot \mathrm{m}^{-2}$ & $2.1 \pm 0.6$ & $2.1 \pm 0.4$ & NS \\
\hline CVP, mm Hg & $12 \pm 6$ & $11 \pm 7$ & NS \\
\hline Mean PAP, mm Hg & $32 \pm 10$ & $37 \pm 12$ & NS \\
\hline PVR, dynes $\cdot \mathrm{s} \cdot \mathrm{cm}^{-5}$ & $287 \pm 192$ & $262 \pm 194$ & NS \\
\hline $\mathrm{SVR}$, dynes $\cdot \mathrm{s} \cdot \mathrm{cm}^{-5}$ & $1126 \pm 442$ & $1107 \pm 330$ & NS \\
\hline PCWP, mm Hg & $21 \pm 7$ & $24 \pm 10$ & NS \\
\hline Bilirubin, mg/dL & $2.8 \pm 0.7$ & $1.6 \pm 0.6$ & NS \\
\hline Aspartate aminotransferase, IU/L & $84 \pm 58$ & $66 \pm 42$ & NS \\
\hline $\mathrm{BUN}, \mathrm{mg} / \mathrm{dL}$ & $82 \pm 46$ & $84 \pm 43$ & NS \\
\hline Creatinine, mg/L & $1.6 \pm 0.7$ & $2.0 \pm 1.1$ & NS \\
\hline $\mathrm{CRP}, \mathrm{mg} / \mathrm{L}$ & $6.2 \pm 2.9$ & $9.2 \pm 15.6$ & NS \\
\hline No. of inotropes & $2.3 \pm 0.8$ & $2.8 \pm 1.2$ & NS \\
\hline IABP, n (\%) & $10(63)$ & $7(70)$ & NS \\
\hline Mechanical ventilation, $\mathrm{n}(\%)$ & $5(31)$ & $4(40)$ & NS \\
\hline Hemofiltration, $\mathrm{n}(\%)$ & $4(27)$ & $3(30)$ & NS \\
\hline Michigan RV risk score & $3.0 \pm 2.4$ & $2.0 \pm 1.7$ & .08 \\
\hline \multicolumn{4}{|c|}{$\begin{array}{l}\text { Numeric data are expressed as means } \pm \text { standard deviation. } R V A D \text {, Right ventricular } \\
\text { assist device; } L V \text {, left ventricular; } C V P \text {, central venous pressure; } P A P \text {, pulmonary } \\
\text { artery pressure; } P V R \text {, pulmonary vascular resistance; } S V R \text {, systemic vascular resis- } \\
\text { tance; } P C W P \text {, pulmonary capillary wedge pressure; } B U N \text {, blood urea nitrogen; } \\
C R P \text {, C-reactive protein; } I A B P \text {, intra-aortic balloon pump; } R V \text {, right ventricular; } \\
N S \text {, not significant. }\end{array}$} \\
\hline
\end{tabular}

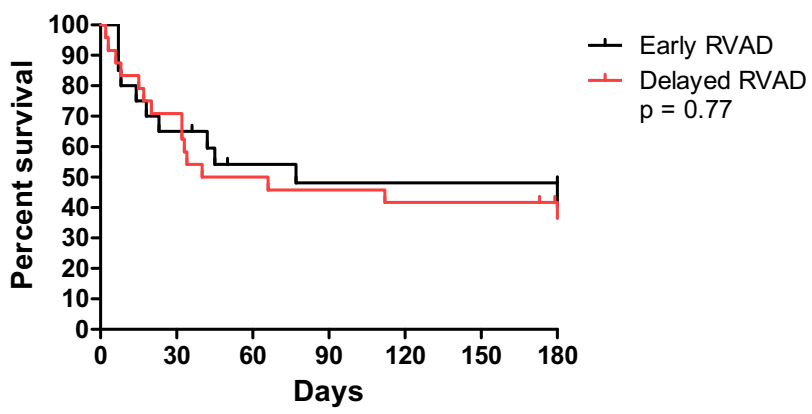

FIGURE 1. Six-month Kaplan-Meier actuarial survivals. RVAD, Right ventricular assist device.

and $44 \%$ in the late temporary RVAD group $(P=.77$; Figure 1).

Outcomes are reported in Figure 2.

\section{DISCUSSION}

We report here the largest ever series of LVAD recipients with postoperative RV failure managed by temporary RVAD support $(n=45)$. The incidence of RV failure after LVAD in our series was $16 \%$, similar to the values reported in previous studies. ${ }^{2-4}$

LVAD treatment in patients with end-stage heart failure can exacerbate pre-existing RV failure by increasing preloading, transiently increasing the pulmonary vascular resistance related to cardiopulmonary bypass, and decompressing the left ventricle with septal shift. ${ }^{6}$ However, the right ventricle can recover, and this justifies the use of temporary RV mechanical support as a strategy for managing RV failure occurring shortly after LVAD implantation.

Weaning from RVAD support was possible in $9(20 \%)$ patients in this study. This rate is lower than those in previous studies, ${ }^{8,9,11}$ which reported RVAD weaning rates of

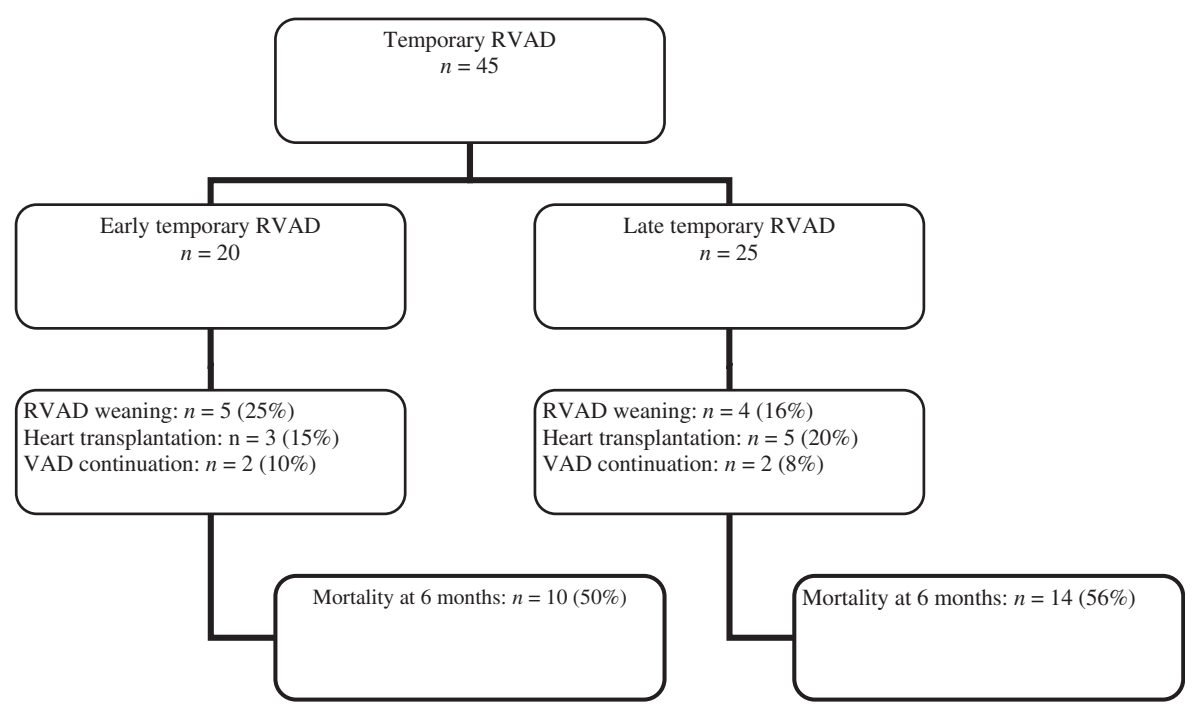

FIGURE 2. Outcomes. RVAD, Right ventricular assist device; $V A D$, ventricular assist device. 
TABLE 5. Review of studies of temporary RVAD use in LVAD recipients

\begin{tabular}{|c|c|c|c|c|c|}
\hline First author & Study period & No. of patients & Support time & Weaning from RVAD & Mortality \\
\hline Dang $^{12}$ & $1996-2004$ & 14 & $13 \pm 17^{*}$ & - & $9 / 14(64 \%)$ \\
\hline Shuhaiber ${ }^{10}$ & 2004-2006 & 5 & $26.6(4-51)$ & - & $5 / 5(100 \%)$ \\
\hline Bhama $^{11}$ & $2005-2008$ & 12 & $8 \pm 8^{*}$ & $7 / 12(58 \%)$ & $7 / 12(58 \%)$ \\
\hline John ${ }^{9}$ & 2009 & 12 & $14(1-29)$ & $6 / 12(50 \%)$ & $8 / 12(67 \%)$ \\
\hline Haneya $^{8}$ & $2008-2011$ & 8 & $14(12-14)$ & $6 / 8(75 \%)$ & $2 / 8(25 \%)$ \\
\hline
\end{tabular}

RVAD, Right ventricular assist device; $L V A D$, left ventricular assist device. *Data are expressed as means \pm standard deviation or medians with interquartile ranges.

between $50 \%$ and $75 \%$. This low rate may be explained by our strategy. At our center, patients who cannot be weaned from RVAD are directly placed on the high emergency list for heart transplantation, provided they have no contraindication for this procedure. Thus, $8(17 \%)$ of our patients underwent transplantation. In the other studies, the patients initially underwent permanent RVAD implantation to bridge the gap to heart transplantation. ${ }^{9-12}$ The mean duration of RVAD support was greater in our study than in previous studies $^{8-12}$ owing to this strategy, inasmuch as the mean time to high emergency transplantation in Germany is 3 months. Despite this longer time on RVAD support, the frequency of complications was similar to that reported by Bhama, ${ }^{11}$ Dang, ${ }^{12}$ John, ${ }^{9}$ and their associates.

Mortality at 6 months was also similar to that reported in previous studies (Table 5). Bhama and associates ${ }^{11}$ reported a late mortality of $58 \%$ in 12 VAD recipients with temporary RVAD implants between 2005 and 2008. In a similar study describing 12 LVAD patients receiving temporary RVAD, mortality at 6 months was $67 \% .{ }^{9}$ However, 1 study, conducted by Shuhaiber and colleagues ${ }^{10}$ on 5 patients, reported a higher mortality $(100 \%)$ in patients with temporary RVAD support. In this study, $3(60 \%)$ patients underwent late implantation, between the 3 and 9 days after LVAD implantation. ${ }^{10}$

Recent studies have demonstrated that better results are obtained with early than with late RVAD implantation. Fitzpatrick and coworkers ${ }^{13}$ found, in a study of 99 patients with permanent BiVAD, that better results were obtained for planned BiVAD implantation than for late BiVAD implantation. In the study conducted by Morgan and colleagues ${ }^{14}$ on 17 LVAD recipients requiring RVAD, 7 (70\%) of the patients in the early RVAD implantation group were subsequently able to undergo transplantation versus $4(57.1 \%)$ of the 7 patients who underwent late RVAD implantation $(P<.001)$. Haneya and associates ${ }^{8}$ reported their experiences with 8 LVAD patients undergoing temporary RVAD implantation, 7 of whom underwent the procedure during the perioperative period. Five $(63 \%)$ of these patients were subsequently discharged from the hospital.

We found no difference in the frequency of adverse events and mortality as a function of the timing of RVAD implantation in our patients on temporary RVAD support, probably because of the relatively small number of patients in this series.
In our study, the mortality of LVAD patients requiring RVAD remained higher than that in patients undergoing LVAD implantation only. The condition of these patients was more severe at the time of LVAD implantation. They were more likely to have intra-aortic balloon pumps, mechanical ventilation and hemofiltration, greater impairment of renal and liver function, and a higher Michigan RV risk score. The occurrence of RV failure after LVAD implantation remains a severe complication associated with excess mortality.

Some univariate risk factors for death were identified, reflecting the severity of heart failure in these patients (high blood urea nitrogen and C-reactive protein concentrations, preoperative mechanical ventilation, preoperative hemofiltration). Destination therapy was also identified as a risk factor for death. In future trials, it will be important to evaluate the predictors of recovery. It is currently difficult to choose between LVAD with temporary RVAD and primary BiVAD support. Inasmuch as there is currently no approved BiVAD device available for destination therapy, only LVAD can be offered to this population of patients.

In conclusion, the development of RV failure in LVAD recipients remains a serious problem, associated with high mortality. Temporary RV mechanical support is an acceptable approach to the management of postoperative RV failure in LVAD recipients.

\section{References}

1. Rose EA, Gelijns AC, Moskowitz AJ, Heitjan DF, Stevenson LW, Dembitsky W, et al., Randomized Evaluation of Mechanical Assistance for the Treatment of Congestive Heart Failure (REMATCH) Study Group. Long-term use of a left ventricular assist device for end-stage heart failure. $N$ Engl J Med. 2001;345: 1435-43.

2. Tsukui H, Teuteberg JJ, Murali S, McNamara DM, Buchanan JR, Winowich S, et al. Biventricular assist device utilization for patients with morbid congestive heart failure: a justifiable strategy. Circulation. 2005;112:I65-72.

3. Matthews JC, Koelling TM, Pagani FD, Aaronson KD. The right ventricular failure risk score a pre-operative tool for assessing the risk of right ventricular failure in left ventricular assist device candidates. J Am Coll Cardiol. 2008;5: 2163-72.

4. Kormos RL, Teuteberg JJ, Pagani FD, Russell SD, John R, Miller LW, et al., HeartMate II Clinical Investigators. Right ventricular failure in patients with the HeartMate II continuous-flow left ventricular assist device: incidence, risk factors, and effect on outcomes. J Thorac Cardiovasc Surg. 2010;139:1316-24.

5. Cleveland JC Jr, Naftel DC, Reece TB, Murray M, Antaki J, Pagani FD, et al. Survival after biventricular assist device implantation: an analysis of the Interagency Registry for Mechanically Assisted Circulatory Support database. J Heart Lung Transplant. 2011;30:862-9.

6. Craig ML. Management of right ventricular failure in the era of ventricular assist device therapy. Curr Heart Fail Rep. 2011;8:65-71. 
7. Loforte A, Montalto A, Lilla Della Monica P, Musumeci F. Simultaneous temporary CentriMag right ventricular assist device placement in HeartMate II left ventricular assist system recipients at high risk of right ventricular failure. Interact Cardiovasc Thorac Surg. 2010;10:847-50.

8. Haneya A, Philipp A, Puehler T, Rupprecht L, Kobuch R, Hilker M, et al. Temporary percutaneous right ventricular support using a centrifugal pump in patients with postoperative acute refractory right ventricular failure after left ventricular assist device implantation. Eur J Cardiothorac Surg. 2012;41: 219-23.

9. John R, Long JW, Massey HT, Griffith BP, Sun BC, Tector AJ, et al. Outcomes of a multicenter trial of the Levitronix CentriMag ventricular assist system for short-term circulatory support. J Thorac Cardiovasc Surg. 2011;141:932-9.

10. Shuhaiber JH, Jenkins D, Berman M, Parameshwar J, Dhital K, Tsui S, et al. The Papworth experience with the Levitronix CentriMag ventricular assist device. J Heart Lung Transplant. 2008;27:158-64.
11. Bhama JK, Kormos RL, Toyoda Y, Teuteberg JJ, McCurry KR, Siegenthaler MP Clinical experience using the Levitronix CentriMag system for temporary right ventricular mechanical circulatory support. J Heart Lung Transplant. 2009;28: 971-6.

12. Dang NC, Topkara VK, Mercando M, Kay J, Kruger KH, Aboodi MS, et al. Right heart failure after left ventricular assist device implantation in patients with chronic congestive heart failure. J Heart Lung Transplant. 2006;25:1-6.

13. Fitzpatrick JR III, Frederick JR, Hiesinger W, Hsu VM, McCormick RC Kozin ED, et al. Early planned institution of biventricular mechanical circulatory support results in improved outcomes compared with delayed conversion of a lef ventricular assist device to a biventricular assist device. J Thorac Cardiovasc Surg. 2009;137:971-7.

14. Morgan JA, John R, Lee BJ, Oz MC, Naka Y. Is severe right ventricular failure in left ventricular assist device recipients a risk factor for unsuccessful bridging to transplant and post-transplant mortality. Ann Thorac Surg. 2004;77:859-63. 